\title{
PUBLICIDAD INTERRUMPIDA. \\ ANÁLISIS CULTURAL DE LA COMUNICACIÓN PUBLICITARIA EN \\ INTERNET
}

\section{Advertising interrupted. Cultural analysis on online advertising communication}

\section{Publicidad interrompida. Análise cultural da comunicação publicitária na internet}

\author{
Javier García López ${ }^{1}$ \\ Pedro A. Hellín Ortuño ${ }^{2}$
}

\section{Resumen}

El objetivo de este trabajo es analizar el proceso de comunicación publicitaria en Internet desde una perspectiva cultural. Investigaciones recientes demuestran que este tipo de publicidad genera una comunicación con el receptor-consumidor caracterizada por estallidos cortos, descoordinados y solapados. Desde el método de la argumentación filosófica práctica nos vamos a adentrar en la disección del proceso de cambio de paradigma publicitario para explicar cómo se están modificando los procesos de comunicación publicitaria en Internet.

Palabras clave: publicidad, internet, interrupción, consumo, ética.

\begin{abstract}
The aim of this paper is to analyze online advertising communication process through cultural perspective. Recent research shows that this type of advertising generates a communication characterized by short, uncoordinated and overlapping bursts. Since practice philosophical argumentation method, we will analyze the process of changing advertising paradigm to explain how they are changing processes of advertising communication on the Internet.
\end{abstract}

Keywords: advertising, internet, interruption, consumption, ethics.

\footnotetext{
${ }^{1}$ Profesor Contratado Doctor de la Universidad a Distancia de Madrid. E-mail: javiergarcialopez.dr@gmail.com

${ }^{2}$ Profesor Titular de la Universidad de Murcia. E-mail: phellin@um.es
} 
Publicidad interrumpida: Análisis cultural de la comunicación publicitaria en internet

\section{Resumo}

O objetivo deste artigo é analisar o processo de comunicação publicitária na Internet a partir de uma perspectiva cultural. Pesquisas recentes mostram que este tipo de publicidade gera uma comunicação com o receptor-consumidor caracterizada por golpes curtos, descoordenados e sobrepostos. Desde o método de argumentação filosófica prática vamos mergulhar em dissecar o processo de mudança de paradigma da publicidade para explicar como eles estão mudando processos de comunicação publicitária na Internet.

Palavras-chave: publicidade, internet, interrupção, consumo, ética.

\section{INTRODUCCIÓN}

En los últimos años, la Red se ha configurado como uno de los principales medios publicitarios, por encima de otros medios tradicionales como la prensa o la radio. La potencialidades de comunicación de Internet parecen importantes y las posibilidades multimedia son también muchísimas. Sin embargo, es necesario incidir en el aspecto esencial de este entorno como medio publicitario, y que generalmente no se suele tener en cuenta desde ciertos ámbitos empresariales surgidos de la misma Red: Internet parece un buen lugar para publicitase, porque todas las grandes empresas de éxito del mundo lo hacen. Se ha generalizado la idea de que una empresa, marca, institución u organismo no puede permitirse el lujo de publicitarse en Internet. Los anunciantes se relacionan con el receptor-consumidor mucho más, en términos cuantitativos (Muela Molina 2007:198). Sin embargo, diversas investigaciones recientes exponen que no se deben exagerar las potencialidades persuasivas del entorno digital (Neumann 2012). Es decir, en términos cualitativos, es posible que la recepción del mensaje publicitario se vea interrumpida por el exceso de estímulos de las pantallas conectadas (Area y Ribeiro 2012:13-19). El ambiente parece propicio para la publicidad porque da lugar a simultanear formatos que anteriormente era imposible reunir. De este modo, en Internet es habitual encontrarnos en un mismo entorno con espacios audiovisuales, únicamente visuales, únicamente sonoros, todos a la vez, etc. Pero esta naturaleza del medio puede 
Publicidad interrumpida: Análisis cultural de la comunicación publicitaria en internet de Javier García López e Pedro A. Hellín Ortuño

provocar en el receptor una pérdida de atención hacia lo que se pretende transmitir. Dicho de otro modo, es fácil que el receptor se sienta distraído como para prestar atención a la publicidad en Internet.

Las herramientas que proporciona el ambiente Internet suelen determinar nuestra manera de percibir el mundo que nos rodea. La comunicación publicitaria virtual que se desarrolla en el ambiente de Internet plantea ciertas novedades y ventajas frente a otras tecnologías anteriores. Sin embargo, si no es percibida como una mera herramienta, los efectos que puede provocar el uso de la llamada publicidad online puede condicionar el proceso de comunicación con el receptor-consumidor, posiblemente abrumado por el exceso de estímulos publicitarios en red. No obstante, la comunicación en Internet puede condicionar incluso nuestras conexiones neuronales. De hecho, como se ha demostrado recientemente, las relaciones existentes entre los individuos y el ambiente se han reordenado, siguiendo las pautas comunicativas propias del mundo de la Red.

Actualmente se piensa que las tecnologías como Internet son simplemente herramientas, pero en realidad suelen ser medios que determinan el modo en que conocemos el mundo. Anteriormente, otras tecnologías como el alfabeto han determinado a los individuos en su conocimiento de su contexto. Tal es el caso que ofrece Luria en su "Desarrollo histórico de los procesos cognitivos" (2006), donde expone un estudio en el que analiza a gentes de los montes kazajos y que pone de relieve cómo el conocimiento del ambiente es diferente entre los individuos no alfabetizados, los semialfabetizados y los alfabetizados (vale decir, iletrados, semiletrados y letrados).

Esta posición puede hacernos recordar el debate casi encolerizado que se produjo en los años ochenta entre los funcionalistas defensores de la teoría de los usos y gratificaciones y los postestructuralistas partidarios de los estudios culturales, sobre los efectos de la comunicación mediática masiva. Los primeros defendían que los individuos receptores de programas televisivos (y de otros contenidos mediáticos) eran libres para elegir un contenido u otro y, por tanto, la elección para ver un programa de televisión u otro dependía únicamente de la gratificación que los individuos obtenían. Los segundos, por contra, defendían que existía una limitación por parte de la tecnología, guiada por los individuos e instituciones de las que dependía la 
Publicidad interrumpida: Análisis cultural de la comunicación publicitaria en internet

de Javier García López e Pedro A. Hellín Ortuño

programación televisiva. Además, el contenido (cómo se estructuraba la información en televisión y cómo se relacionaban los distintos programas entre sí) daba lugar a un "cierre interpretativo" que fijaba de algún modo cómo debía la audiencia posicionarse ante ciertos temas sociales y ambientales (Morley 1996). De modo que, para los partidarios de los estudios culturales, los medios determinan el modo de conocer el mundo. Contrariamente, para los partidarios de los usos y gratificaciones se trataba sólo de una cuestión de elección racional de la audiencia y este hecho no limitaba el modo de conocer la realidad para los individuos.

Siguiendo los postulados teóricos y prácticos de los estudios culturales, el objetivo de este artículo es ofrecer un análisis sobre el proceso de comunicación que genera la publicidad en el ambiente Internet actual. Un proceso que parece estar determinado por una especie de narración fragmentada que puede interrumpir la comunicación con el receptor-consumidor, dando lugar a una posible paralización de la seducción propia de todo relato publicitario.

\section{PUBLICIDAD Y CONSUMO EN LA ÉTICA DE INTERNET}

En la actualidad, las empresas utilizan los recursos digitales para desarrollar las técnicas de marketing y los consumidores se han convertido en consumidores-digitales (Rowlands, Nicholas et al. 2008:290-310). La esfera de Internet ofrece a los productores de bienes y servicios nuevas posibilidades para ponerse en contacto con un consumidor diferente al de hace unos años. Podemos decir que existe una nueva modalidad de consumidor o, simplemente, un consumidor con necesidades y deseos parecidos al de hace unos años, pero que utiliza los recursos digitales para satisfacer dichas necesidades y deseos. Kotler (2006: 12) explica que los nuevos consumidores tienen cinco nuevas características frente a los consumidores del pasado. Estas nuevas características se pueden resumir como se plantea a continuación: los nuevos consumidores han aumentado su poder de compra, existe una mayor diversidad de bienes y servicios a los que el consumidor tiene acceso, la información sobre cualquier aspecto se ha multiplicado de manera exponencial, el posicionamiento de una marca, un producto o un servicio en la Red es fundamental para las empresas de hoy, los clientes tienen una 
Publicidad interrumpida: Análisis cultural de la comunicación publicitaria en internet

de Javier García López e Pedro A. Hellín Ortuño

mayor facilidad para relacionarse con las empresas, la comunicación sobre las características, beneficios y valores asociados a marcas, productos y servicios se ve potenciada por el acto de compartir vivencias por parte de los consumidores en las redes sociales (Martínez Rodrigo y Sánchez Martín 2011:469-480).

Todo ello pone de manifiesto que la sociedad actual está determinada por las llamadas nuevas tecnologías. Con la incursión de Internet en la década de los años noventa del siglo $\mathrm{XX}$, las relaciones sociales y económicas se han visto fuertemente influidas por la Red y por sus efectos. El mundo de la publicidad y de su industria no han sido ajenos a estos cambios. En España, la publicidad alcanzó su momento creativo (y quizás también en los demás ámbitos de la industria publicitaria) más esplendoroso en los años ochenta y a principios de los años noventa. No en vano, cabe destacar la importancia de las agencias publicitarias españolas en todo el mundo. De hecho, aquellos años fueron también los años del triunfo de los anuncios españoles en los festivales Iberoamericano (El Sol, Festival Iberoamericano de la comunicación publicitaria) y de Cannes (Cannes Lions). La actualidad publicitaria viene marcada por un deterioro creativo que armoniza con la crisis económica mundial de finales de la primera y principios de la segunda décadas del siglo XXI. Las dinámicas del mundo de la publicidad han cambiado. No obstante, también nos encontramos con receptores mucho más habituados a los relatos audiovisuales, perfectamente alfabetizados en el mundo de Internet y ávidos de estímulos suministrados en rápidos golpes discursivos (al modo como todo se precipita en el ambiente de la Red). De igual modo se comporta el mundo del marketing, poniendo en circulación constante nuevos productos y servicios que, tal vez, ni los consumidores ni la publicidad son capaces de digerir.

Tampoco ayuda al ambiente publicitario el declive de los medios de comunicación, en constante cambio y con una crisis en el modelo de negocio que hace debilitar las plantillas de periodístas antaño tan necesarias para crear y facilitar una buena información para construir una buena sociedad. Con esta situación mediática, la inversión publicitaria ha caído en picado (si bien ciertos gurús atisban un repunte de la inversión en publicidad para los próximos años de la segunda década del siglo XXI). En televisión e Internet, a pesar de la crisis, existe una saturación de soportes que tampoco ofrece facilidades a la publicidad, ya que son muchos los espacios disponibles y, por 
Publicidad interrumpida: Análisis cultural de la comunicación publicitaria en internet de Javier García López e Pedro A. Hellín Ortuño

tanto, menor el precio que se paga por la publicidad; sobre todo comparado con lo que se pagaba décadas atrás (Del Pino 2007:299-309). En este contexo, también se ha producido una concentración de la industria publicitaria en grandes conglomerados, generalmente organizados a partir de matrices situadas en Estados Unidos, principalmente, pero también en Francia y Gran Bretaña (los grupos publicitarios más importantes del mundo actualmente son Interpublic Group, Publicis, Omnicom Group, Havas y WPP Group).

Ciertos autores aseguran que "Internet es un instrumento muy útil para detectar las tendencias y necesidades de los potenciales clientes a través de su paso por la web, lo que se debe traducir en un mayor acercamiento anunciante-cliente" (Checa Godoy 2007:193). No obstante, esta aseveración nos indica las bondades del medio para la actividad de marketing, aunque no está tan claro que sea bueno para la actividad comunicativa publicitaria. Cuando navegamos por la Red dejamos nuestro rastro de potenciales consumidores. Las empresas saben que la información es poder y conseguir información sobre posibles receptores y, lo que es mejor, sobre posibles compradores, es un hecho al que no pueden renunciar. En este ambiente, las redes sociales (Twitter, Facebook, Linkedin, e incluso otras redes móviles como Whatshap) se han convertido en plataformas donde las grandes empresas (los conglomerados que manejan las redes económicas mundiales) pueden conseguir datos relevantes sobre nuestros comportamientos y, quizá, sobre nuestros pensamientos, debido a las laxas normativas sobre privacidad que rigen en estos contextos. Sin embargo, y a pesar de lo dicho, ninguna empresa en la actualidad puede evitar la Red como plataforma publicitaria. No estar en Internet supone no estar en la esfera de los receptores y, finalmente, de los consumidores. Alejarse de la web es desaparecer de la mente de los individuos, aunque dicha dinámica esté cambiando el modelo empresarial en todos los sectores (como ocurre con las agencias de viajes, que prácticamente han dado paso a las agencias de viajes por Internet; se podría decir entonces que la Red ha fulminado prácticamente a las agencias de viajes tradicionales).

De este modo, en el análisis del medio Internet como una red de soportes aflora la necesidad de una perspectiva crítica que nos hable sobre los potenciales efectos en perjudiciales para los receptores-consumidores y para la propia comunicación 
Publicidad interrumpida: Análisis cultural de la comunicación publicitaria en internet

de Javier García López e Pedro A. Hellín Ortuño

publicitaria. Se abre una línea de estudio sobre la ética de Internet asociada al relato publicitario.

\section{EL ANÁLISIS CRÍTICO-CULTURAL}

La sociología funcionalista piensa en los medios de comunicación, incluida la publicidad, como instituciones capaces de mantener el orden establecido (Ramón Monje 2013:10-17). Se habla de los medios de comunicación como constructores de democracia. Sin embargo, las escuelas de pensamiento crítico no estiman que este valor democrático esté presente en muchas acciones publicitarias o mediáticas. No obstante, desde estas perspectivas, los medios de comunicación se plantean como medios de producción y transmisión cultural. Ciertas escuelas, desde esta rama de pensamiento, hablarán de los medios de comunicación como instrumentos de poder y dominación o hegemonía (Adorno y Horkheimer 1972; Althusser 1969 y 1975; Marcuse 1985; Gramsci 1985). La perspectiva crítica, en consecuencia, conforma una visión radicalmente opuesta al funcionalismo $\mathrm{y}$, por ende, a la propuesta de los usos y gratificaciones.

Al contrario que la teoría de los usos y gratificaciones, el método crítico para abordar el análisis de los medios de comunicación suele concebir la audienciaconsumidora como un conjunto complejo de subculturas y subgrupos superpuestos, entendiendo que los contextos sociales establecen los marcos conductuales propios de cada individuo. En este sentido, Morley (1996) plantea la necesidad de llevar a cabo una abstracción, una simplificación de la organización de los individuos en sociedad. Para ello, parte de la teoría de Parkin (1974), quien enmarca a los miembros de las diferentes clases sociales de una sociedad dentro de lo que él llama "sistemas de sentido o marcos ideológicos". Aunque, como hemos dicho, el esquema de Parkin es una simplificación, permite concebir la audiencia como un todo estructurado. De esta forma, Morley establece tres posibilidades que el receptor del mensaje puede adoptar en su situación de decodificador: que acepte totalmente el mensaje, que lo comparta en una parte o que se oponga por completo. Morley concluye que la recepción y la interpretación del mensaje dependen en gran medida del contexto social estructurado en el que se inserta el 
Publicidad interrumpida: Análisis cultural de la comunicación publicitaria en internet

de Javier García López e Pedro A. Hellín Ortuño

decodificador individual. Aún así, la lectura dominante que impone el emisor guía la interpretación del texto y, en la mayoría de casos, se impone a una potencial lectura opuesta.

Se podría concluir que la mayoría de los receptores se adhieren de una forma más o menos ajustada al macrodiscurso comunicativo (González Requena 1996), interpreta la posible lectura preferencial de la publicidad en red, porque el uso de Internet es sistemático y generalizado. No hay otro discurso, no hay otra realidad cotidiana que no sea la realidad de los medios de comunicación. Nuestras creencias e intereses surgen a partir de las creencias e intereses de la estructura social y nos impregnamos de ellas como si fueran nuestras. La probabilidad de oposición a este macrodiscurso es menor. La capacidad de reacción por parte de los receptores ante otras posibilidades, ante otras herramientas o ante otras tecnologías es exigua. Se puede argumentar, por tanto, que la publicidad determina ideológicamente a los receptores; guía sus pensamientos y sus conductas (Williamson 1978). Pero el caso de la publicidad en Internet es si cabe más significativo, porque la Red no solo determina ideológicamente, sino que influye en la configuración cerebral, en cómo se organizan nuestras conexiones neuronales (Carr 2014).

\section{LA PUBLICIDAD INTERRUMPIDA}

Debido a la plasticidad del cerebro, sabemos que los medios de comunicación, Internet a la cabeza, está cambiando nuestra mente, nuestras conexiones neuronales (Carr 2008). En este contexto de comunicación virtual, el flujo de información es superior a la capacidad del cerebro para procesarla. Ello nos lleva a una cultura de la inmediatez. El usuario-receptor requiere respuestas rápidas del emisor. Un ejemplo de esta dinámica la encontramos en la comunicación cinematográfica, donde los argumentos de las películas son cada vez más planos. Y las películas que contienen argumentos más trabajados y cuyas conexiones entre elementos audiovisuales parecen más complejas son encasilladas en el llamado cine alternativo. Además, el cine de argumentos cuidados está siendo sustituido masivamente por series de televisión que ofrecen pequeños golpes o shocks argumentales divididos en varios capítulos y 
Publicidad interrumpida: Análisis cultural de la comunicación publicitaria en internet de Javier García López e Pedro A. Hellín Ortuño

temporadas, siguiendo la cadencia de Internet. Por decirlo de algún modo, nos estamos acostumbrando a la cultura de Twitter. No somos capaces de aguantar más de ciento cuarenta caracteres en un proceso de intercambio comunicativo.

Así que la mente lineal (calmada, concentrada) está siendo desplazada por una mente que necesita estallidos cortos, descoordinados y solapados. Se trata de una mente forjada en el hábito del manejo de la Red. Cuando una actividad se repite, como ocurre con el manejo de las nuevas tecnologías, las conexiones neuronales propias de esa actividad se hacen fuertes. Estos cambios en el cerebro no sólo ocurren con experiencias físicas, también con experiencias imaginadas. Lo que pensamos también produce una influencia física en nuestro cerebro. Se producen, como explica Carr (2014), cambios fisiológicos. Dichos cambios se pueden observar en los cerebros de individuos que practican con instrumentos musicales y manejan el lenguaje musical. Por tanto, el cerebro no se limita a olvidar, sino que suple el espacio que dejan las habilidades que ya no se practican por las nuevas; si bien podemos esforzarnos en recuperar las viejas habilidades.

Cada vez leemos menos libros y nuestro cerebro rellena el hueco de la lectura con las nuevas conexiones que surgen de la actividad en la Red. Esto ocurre con cualquier tecnología intelectual, como argumenta Carr. Herramientas como los mapas o el reloj han cambiado la mentalidad de la humanidad. Por ejemplo, el reloj cambió la noción del tiempo para siempre. Las herramientas intelectuales transforman la experiencia y, por tanto, la mente. No obstante, las tecnologías intelectuales imponen una ética, que se transmite, siempre en evolución, de padres a hijos, lo que recuerda a la "memética" de Dawkins (2000).

Pero Internet va más allá que cualquier otra tecnología. Porque la Red subsume la mayoría de tecnologías intelectuales (es libro, es mapa, es reloj, es calculadora, etc.). Pero esta acumulación se manifiesta de una manera fragmentada, que provoca distracción y sobrecarga cerebral. Incluso los demás medios tradicionales, como la televisión o la radio, intentan parecerse cada vez más a la Red: fragmentan la información breve, se encaminan hacia los contenidos centrados en la diversión y se sincronizan con las redes sociales para obtener un efecto interactivo con la audiencia. Sin embargo, este efecto de interacción con el receptor-consumidor no es tan bueno para 
Publicidad interrumpida: Análisis cultural de la comunicación publicitaria en internet

los propósitos publicitarios, ya que con la fragmentación inherente a la comunicación de Internet se interrumpe el proceso de seducción publicitaria. Internet facilita la ruptura del relato publicitario y dificulta el cierre interpretativo del que hablaba Morley (1996).

Dicho lo cual, se puede asegurar que la comunicación publicitaria en Internet está determinada por un cambio de contenido inherente al medio, más allá del cambio de forma, como ya apostilló McLuhan (1964). El acto de recepción publicitaria en la Red puede convertirse en algo superficial, ya que se pierde la magia de sumergirse en otros mundos propios del relato publicitario de los medios convencionales, para lo que se requiere cierta concentración y un contexto tranquilo. Por todo ello, el apego al texto y a la imagen se vuelve muy tenue en Internet y priman los valores del entretenimiento y de la distracción. "Las búsquedas en la Red no dibujan el bosque, ni siquiera árboles. Sólo ramas y hojas" (Carr 2014:115). Esto es lo que proporciona la fragmentación propia de Internet que, a su vez, dificulta el éxito publicitario.

En esta "ecología de la interrupción" (Carr 2014:136), la publicidad en Internet apela constantemente a nuestros sentidos. $\mathrm{Y}$ en ese ambiente, las empresas e instituciones piensan que puede ser un buen medio para publicitarse, ya que el receptorconsumidor está permanentemente conectado a la Red por medio de múltiples dispositivos (ordenador, móvil, tableta, etc.). Pero no se han percatado de que el ambiente Internet provoca una ruptura del relato de todo anuncio publicitario que dificulta el cierre interpretativo y, por ende, el proceso de decodificación por parte de la audiencia.

Se establecen generalmente como objetivos publicitarios la notoriedad, un cierto posicionamiento en la mente del receptor y potencial consumidor, la generación de una imagen buena de nuestra empresa, marca, institución u organismo. Pero ello únicamente se puede conseguir si el receptor es capaz de recordar nuestra comunicación, nuestra publicidad. Para que esto ocurra, la publicidad debe ser memorable, ha de ocupar un pequeño hueco en el cerebro de la audiencia. Como escribe Carr, "el hecho de que un gen deba estar activo para formar la memoria a largo plazo muestra claramente no sólo que los genes son los factores determinantes del comportamiento, sino también del entorno, caso del aprendizaje" (2014:228). Esto es muy importante para explicar cómo ambientes estimulantes ayudan en el proceso de aprendizaje $y$, por tanto, a 
Publicidad interrumpida: Análisis cultural de la comunicación publicitaria en internet

de Javier García López e Pedro A. Hellín Ortuño

retener/memorizar. Con la saturación publicitaria de la Red, como decimos, el exceso de estímulos y de información hace que nuestra atención se disperse. Por ello, como explican Wells, Moriarty y Burnett (2007:108), “cuando se recuerda el mensaje del anuncio, no solo se recuerda haber visto el anuncio, sino que también se recuerdan los puntos del copy, que es la información que se da acerca del producto [la información simbólica]. Pensar en el anuncio es una forma de procesar la información que ayuda a anclar las ideas en la memoria". Para retener, para memorizar, el cerebro debe transferir la memoria de trabajo a la memoria a largo plazo. Esta es la clave de la tradición oral; todo ornamento poético estaba dirigido a la retentiva (el acto pedagógico), a que el receptor recordara y se identificara con los comportamientos épicos que se repetían de diferentes modos con la intención de ser recordados. La tradición oral estimulaba la atención con el objetivo de la memorización. Sin embargo, en la actualidad, debido a la cantidad de datos e información que se ofrecen en Internet (incluso de manera simultánea), la memorización es casi imposible. Navegar por Internet, al contrario que ocurre con la lectura de un libro, de un diario o de una revista, no implica relaciones con el lenguaje, la memoria y el procesamiento visual. Se forja una ética de lo fugaz.

De modo que, con la publicidad online, la capacidad de memorización de los individuos se debilita enormemente. No se puede obviar que lo importante no es que el potencial consumidor recuerde a corto plazo un anuncio. Lo verdaderamente significativo para la publicidad es que consiga provocar en el receptor una memorización de nuestro mensaje a largo plazo. Algunos autores opinan que, en el ambiente publicitario, "el futuro es más un diálogo, una conversación entre el fabricante y su cliente, que un simple envío y recepción de mensajes comerciales, impersonales e indiscriminados" (Muela Molina 2008:183-201). Pero las investigaciones empíricas como las que hemos mencionado nos hablan del medio Internet como un lugar en el que la comunicación entre el emisor y el receptor se ve constantemente interrumpida. El diálogo entre anunciantes y receptores es más bien una quimera desde el punto de vista del relato publicitario tradicional. 
Publicidad interrumpida: Análisis cultural de la comunicación publicitaria en internet

de Javier García López e Pedro A. Hellín Ortuño

\section{CONCLUSIONES}

En el ambiente socioeconómico actual, el medio Internet está vehiculando la nueva dinámica del mercado publicitario. Quizá sea cierto que Internet se configura como un buen medio para que los anunciantes se acerquen al receptor-consumidor, incluso conociendo sus gustos, sus comportamientos económicos y sus pensamientos potenciales sobre el consumo. Pero únicamente pone de relieve la importancia del medio online para las acciones de marketing. Sin embargo, la comunicación publicitaria no parece verse favorecida por la ética de Internet, esa pauta de pensamiento y comportamiento sustentada en el gusto por lo fugaz y por lo fragmentado. Es verdad que la Red es un medio barato para publicitarse y que los productos y servicios están en el escaparate global de un modo permanente. Pero el relato, la construcción y la recepción narrativas se ve negativamente afectada por la idiosincrasia del medio y por los efectos que provoca en nuestro modo de interacción y en nuestra memoria.

La ética de Internet es una ética de lo fugaz, de lo vago. Es una pauta de pensamiento y de acción que se está imponiendo como la única ética. Y esto no es ni mucho menos una vuelta a la ética de la tradición oral, que guiaba a los receptores por medio de la comunicación de las tramas épicas que se recogen, por ejemplo, en los compendios del rapsoda Homero (ese sastre real o ficticio de la poesía épica). Y tampoco tiene que ver la comunicación en Red con la comunicación escrita, en ese sentido. Porque la lectura tranquila subestima los sentidos e Internet los sobrestima. La mímesis necesaria para la comunicación simbólica de la publicidad se debilita por completo en el medio Internet.

Con la Red tenemos más habilidades visual-espaciales, pero debilitamos el pensamiento profundo y, por ende, el proceso de recepción de los relatos publicitarios fuertes, sustentados en una construcción simbólica en la que confluyen ambientes y personajes necesarios para seducir al receptor. Se está forjando una ideología de la Red, pero que sirve para la misma Red y para los contextos vivenciales de fuera de la Red. No podemos negar que vivimos en un proceso de cambio de paradigma tecnológico. La escritura alfabética supuso una revolución y coexistió con la tradición oral (según algunos autores, incluso hasta la Edad Media). Con la aparición de la imprenta, la 
Publicidad interrumpida: Análisis cultural de la comunicación publicitaria en internet

de Javier García López e Pedro A. Hellín Ortuño

tradición oral se diluyó por completo y el libro se impuso como medio de transmisión y como ética. Ahora estamos inmersos en un nuevo cambio tecnológico a niveles revolucionarios, ya que nuestra ética está cambiando. En este contexto, el discurso tradicional de la publicidad, sustentado en la forja de relatos persuasivos mediante lo simbólico, se debilita en la fragmentada y fugaz comunicación en red.

\section{REFERENCIAS BIBLIOGRÁFICAS}

ADORNO, T. W. \& HORKHEIMER, M. "The Culture Industry: enlightnment as Mass Deception", in ADORNO, T. W. y HORKHEIMER, M. (Eds.). Dialectic of enlightenment. New York, Herder \& Herder, 1972.

ALTHUSSER, L. For Marx. London, Allen Lane, 1969.

ALTHUSSER, L. Escritos. Barcelona, Laia, 1975.

AREA, M. \& RIBEIRO, T. "De lo sólido a lo líquido: las nuevas alfabetizaciones ante los cambios culturales de la web $2.0^{\prime \prime}$ in Comunicar, $\mathrm{n}^{\circ} 38$, vol. 19, Huelva, 2012, p. 13-20.

CARR, N. "Is Google making us stupid?" in The Atlantic, Washington, july/agoust/2008. Disponible en <http://www.theatlantic.com/magazine/archive/2008/07/is-google-making-usstupid/306868/>. Aceso en: 3/2/2016

CARR, N. Superficiales. ¿Qué está haciendo Internet con nuestras mentes? Madrid, Taurus, 2014.

DAWKINS, R. El gen egoísta. Barcelona, Salvat, 2000.

DEL PINO, C. "El anunciante en la era de la saturación publicitaria: Nuevas herramientas de comunicación" in Ámbitos, nº 16, Sevilla, 2007, p. 299-309.

GONZÁLEZ REQUENA, J. El discurso televisivo: espectáculo de la postmodernidad. Madrid, Cátedra, 1999.

GRAMSCI, A. La política y el Estado moderno. Barcelona, Planeta-Agostini, 1985.

LURIA, A. R. Desarrollo histórico de los procesos cognitivos. Madrid, Akal, 2006.

MARCUSE, H. El hombre unidimensional. Ensayo sobre la ideología de la sociedad industrial avanzada. Barcelona, Planeta-Agostini, 1985. 
Publicidad interrumpida: Análisis cultural de la comunicación publicitaria en internet

MARTÍNEZ-RODRIGO, E. \& SÁNCHEZ MARTÍN, L. "Publicidad en Internet: nuevas vinculaciones en las redes sociales" in Vivat Academia, ${ }^{\circ}$ 117, Madrid, 2011, p. 469-480.

McLUHAN, M. Understanding media. The extensions of man. New York, McGrawHill, 1964.

MORLEY, D. Televisión, audiencias y estudios culturales. Madrid, Amorrortu, 1996.

MUELA MOLINA, C. "La publicidad en Internet: situación actual y tendencias en la comunicación con el consumidor" in Zer, $\mathrm{n}^{\circ}$ 24, vol. 13, Leioa, 2008, p. 183201.

NEUMANN, J. von. The computer and the brain. New Haven, Yale University Press, 2012.

PARKIN, F. The Social Analysis of Class Structure. London, Routledge, 1974.

RAMÓN MONJE, L. M. "Funcionalismo. Del poder, la guerra y otras necedades" in Revista Ciencias Básicas Bolivarianas, nº 14, Barranquilla, 2013, p. 10-17.

ROWLANDS, I.; NICHOLAS, D. et al. "The Google generation: the information behaviour of the researcher of the future" in Aslib Proceedings: New Information Perspectives, $\mathrm{n}^{\circ}$ 4, vol. 60, Bingley, p. 290-310.

Artigo submetido: 06/05/2016

Artigo aprovado: 17/06/2016 